\title{
The Orientation of Urban Image and the Strategy of Cultural Communication
}

\author{
Yue Huang ${ }^{1,}$, Shuai Yang ${ }^{1,2, b}$ \\ ${ }^{1}$ Zhuhai College of Jilin University, Zhuhai 519041, China \\ ${ }^{2}$ City University of Macau, Macau, China \\ ahuangyue13597@hotmail.com, b26330587@qq.com
}

Keywords: design, city, image, city culture, city image orientation, city image transmission.

\begin{abstract}
From the definition of urban image, the image of the city is very broad, from its natural geographical environment, social security situation, economic and trade level, building landscape, transportation, business, education and other facilities, Government governance model, historical and cultural traditions to the people's quality of life, values and behavior, etc., all belong to a city image awareness. In general, the city image is a city history and culture and visual characteristics of the comprehensive show. The city image of the accurate positioning can effectively highlight the characteristics and connotation of a city. The overall paradigm of urban image transmission is to make full use of the self-shaping and others in the urban orientation and the binary tension of the image elements to form a preferred strategy. Through the construction of urban characteristics, accurate positioning of the city image, attracting more and more external resources and urban audience, the purpose is to promote the city's economic and cultural development. In the process of urban image planning, the government should combine the local geographical characteristics, landscape characteristics and cultural background, and make a rigorous, regional and effective construction and dissemination of the local cultural background.
\end{abstract}

\section{City brand positioning}

Urban positioning is the basic part of urban image design, but also the most important part of the city is a concentrated expression of the image, reflecting a city's unique and cultural conservation. If the tree with a metaphor for the construction of urban image, urban positioning is the root, follow-up operations are branches and leaves, no roots of the roots simply not flourish. In fact, how a city's development, with its image positioning is accurate with a direct relationship between the city positioning decision development direction, development strategy and development of the initiatives. Accurate urban positioning can make the city image occupy a place in the fierce competition in the market, and better attract a large number of external resources and urban audience to promote urban economic development.

As an extension of the core values of urban positioning and refinement of urban image elements, effective urban marketing requires the establishment of a consistent and consistent urban brand positioning. Generally speaking, the city brand positioning will be through the city's visual image and cultural image of the two parts to express it, the city's visual image is projected to the target group of the brain generated by the visual "image", that is, the urban image design in the public can see with the naked eye part of the excellent visual expression to the public to leave a good impression of the city, is the embodiment of the characteristics of urban values, but also the city of the public and the value of the commitment of the viewer. And for the shaping of urban culture, is to re-shape the history, the designer should uphold a heritage of responsibility, carry forward the unique regional culture.

The design of city image, should be people-oriented, from the public will instead of the designer's subjective intention, so is the image positioning, empathy is particularly important to follow the public on shaping the image of the city will, will be people-oriented through the positioning of the city always, so that each city has its own value, to avoid the image of the city similar and close. 
Accurate urban positioning strategy has important practical significance in shaping the image of the city.

\section{Urban cultural strategy}

City culture strategy is in the city of the image elements of resources extraction and explore can reflect the spirit of the city geographic and cultural identity, content and means for city image communication. Urban culture is the source of city image, the essence, abstraction and accumulation of city image, and the spiritual image of the city. It is the core and soul of city image. The dissemination of urban image needs to respect individuality, expand cultural consensus and seek common ground while reserving differences. Thirdly, the dissemination of urban image needs to create cultural context and refine cultural identity.

City culture can reflect a city spirit connotation, is a period of history, is a heritage, a long-term accumulation process, however, the image of the city should be in the mining of lateral thinking at the same time, combined with the vertical thinking, into the city's past, present and future, to the continuation of history to show the process of development of city the connotation, through the image of the city. Review and analyze the image of the city context make the city have highlights the essence of heritage, to preserve and continue and refined, and provides a model and basis for city culture inheritance and continuity and city image expression and communication. Reviewing the history and looking forward to the future, we can demonstrate the characteristics of a city, and provide a realistic basis for the refinement of folk culture, the construction of spiritual home, the enhancement of the market competitiveness of the city and the dissemination of the brand image of the city.

\section{Urban image communication}

The core task of urban image communication is to establish the image of urban communication which embodies the unique core value of the city, and to achieve the purpose of propagating the target audience in the communication with the city image. The establishment of the image of urban communication is often separated from the image of the natural attribute of "urban product", which is a concentrated expression of the city's unique folklore, culture and values based on the "city product" innovation function. The aim of the core task of urban image communication, one is to maximize the image of urban communication, that is, through the planning of urban activities in the form of urban image to give new ideas and new experience of the association. Second, maximize the scope of identification. Use the media PR strategy, use the public base to expand the audience and deepen the audience's influence. With the continuous development of new technological revolution, information, humanities, economy and other rapid development, communication technology, means of expression, design methods and other aspects of the times are changing. High tech, represented by Internet of things and cloud computing, as an important component of the new generation of information technology, is on the stage of history, and is also an important stage of development in the era of information technology. The realization of high-tech technology on the city's image more and more diversified, traditional media advertising; new media technology such as virtual reality, sound and light art; and public relations, marketing tools and other means of effective combination of information dissemination, so that the image of the city to become efficient.

\section{References}

[1] https://baike.so.com/doc/6284016-6497485.html

[2] He Guoping. City image communication: framework and strategy

[3] [US] Lewis Mumford: "Urban History --- origin, evolution and prospects", Song Junling translation, China Construction Industry Publishing, 2005 
[4] Liu Lu: "On the city image communication concept innovation path and strategy", urban development research, 2009 the first 11

[5] Chen Liuqin: the connotation of the image of the city, positioning and its effective communication, Tianjin Institute of Social Sciences, Urban Economics 2010 